Title:

\title{
OPA1 in lipid metabolism: Function of OPA1 in lipolysis and thermogenesis of adipocytes
}

\author{
Dinh-Toi Chu ${ }^{1,2,5,6}$, Yang Tao ${ }^{7}$ and Kjetil Taskén ${ }^{1,2,3,4, *}$ \\ ${ }^{1 .}$ Biotechnology Centre, University of Oslo, Oslo, Norway \\ 2. Centre for Molecular Medicine Norway, Nordic European Molecular Biology Laboratory Partnership, \\ University of Oslo and Oslo University Hospital, Oslo, Norway \\ ${ }^{3 .}$ K.G. Jebsen Inflammation Research Centre; University of Oslo; Oslo, Norway \\ 4. Department of Infectious Diseases; Oslo University Hospital; Oslo, Norway \\ ${ }^{5 .}$ Institute for Research and Development, Duy Tan University, K7/25 Quang Trung, Danang, Vietnam \\ ${ }^{6}$ Faculty of Biology, Hanoi National University of Education, Hanoi, Vietnam \\ 7. College of Food Science and Technology, Nanjing Agricultural University, Nanjing 8 210095, China \\ *Correspondence to: Dr. Kjetil Taskén email: kjetil.tasken@ncmm.uio.no
}

\begin{abstract}
OPA1 (Optic Atrophy 1) is a mitochondrial GTPase known to regulate fission of mitochondria. It was recently also shown to locate on lipid droplets in adipocytes where it functions as an A-kinase anchoring protein (AKAP) that mediates adrenergic control of lipolysis by facilitating PKA phosphorylation of perilipin (Plin1). In brown adipocytes indirect evidence support the notion that OPA1 regulation of fission serves to increase thermogenesis, which thereby contributes to dissipation of energy. In white adipocytes OPA1 located on lipid droplets serves as a gatekeeper to control lipolysis induced by adrenergic agonists. However, the function of OPA1 in lipolysis and thermogenesis in inducible brown adipocytes (brite/beige cells) remains elusive. Here we discuss the role of OPA1 in lipid metabolism.
\end{abstract}

Keywords: OPA1, AKAP, cAMP, lipid metabolism, brown adipocyte, white adipocyte

Running title: OPA1 in lipolysis and thermogenesis

\section{Types of adipocytes and their function in fat metabolism}

Both humans and rodents have two basic types of adipocytes, white and brown cells, the names of which refer to their presence in white adipose tissue (WAT) and brown adipose tissue (BAT), respectively (Figure 1). The white and brown cells have diametrically opposite roles in controlling the energy balance 
of the organism and they can also co-exist in the same fat depots. In mice, a recent publication by Walden et al [1] identified 15 different types of fat depots with variable composition of adipocytes. Whereas some adipose tissues were found to be of only brown or white cells, other depots were composed of a mixture of brown and white adipocytes [1]. White adipocytes function to accumulate lipids for energy storage, while brown adipocytes burn lipids to serve the thermogenic requirements of the body [2]. Brown fat cells can be divided into classical brown and inducible brown adipocytes, two subtypes of brown cells that share several molecular characteristics and may serve the same function in lipid metabolism, but are developed from different precursors [3-7] (Figure 1).

Excess lipid storage in WAT resulting from the imbalance between food intake and energy expenditure is the major cause of obesity. The location of WAT depots varies among species, in mammals the most abundant sites of lipid storage are subcutaneous and visceral fat depots [8,9]. The anatomical location of WAT determines the types of obesity and it related metabolic disorders in the excess energy conditions $[8,9]$. In humans, the accumulation of extra fat under the skin results in subcutaneous or "pear-shape" obesity, whereas excess storage of lipids around the visceral organs causes visceral or "apple-shape" obesity [8]. Pear-shape obesity comes with lower risk of diabetes and metabolic disorders compared to visceral obesity [8]. With respect to molecular signatures, white adipocytes share the expression of homeo box C8 (Hoxc8) with inducible brown adipocytes [1], but they are distinguished from brown cells by expression of high levels of adipose expansion genes such as specific transcript (Mest), secreted frizzled related protein 5 (Sfrp5), bone morphogenetic protein 3 (BMP3) and caveolin 1 (Cav1) especially in a response to an obesogenic diet [10-15].

Classical brown adipocytes in mammals reside in depots such as the interscapular brown adipose tissue (iBAT) - the biggest brown adipose tissue. They are present in the newborn and small mammals as an adaptive organ to maintain body temperature in hypothermic conditions. These adipocytes function to transfer energy from food into heat $[2,16]$ for warming the body in the early days of life and during hibernation in the winter. In humans, several recent reports confirm the existence of active classical brown adipocytes also in adults [17-23]. However, whereas the iBAT is most developed in infants, regresses in childhood and is absent in adults, humans may to a varying degree retain BAT in the neck region also as adults [23-25]. Classical brown adipocytes express genes for non-shivering thermogenesis such as uncoupling protein 1 (Ucpl), peroxisome proliferator-activated receptor- $\gamma$ coactivator-1 $\alpha$ (Pgcl $\alpha)$, and peroxisome proliferator-activated receptor alpha (Ppara) at high levels [2,7,21,22,26-32]. Furthermore, cerebellum 1 (Zicl) is identified as a specific marker for BAT [29]. 
Inducible brown adipocytes are generated in white fat depots in response to cold exposure or treatment with $\beta$-adrenergic receptor agonists in vivo [32-36]. These brown fat cells can be differentiated in vitro from preadipocyte cell lines and stem cells by adipogenic medium supplemented with one or more "browning" reagents such as norepinephrine, thiazolidinediones, natriuretic peptides, fibroblast growth factor 21 (Fgf21), Irisin and bone morphogenic protein 7 (Bmp7) [5,15,24,31,32,37-47]. This subtype of brown fat cells is called brite adipocytes, beige adipocytes, brown-like fat cells or induced-brown adipocytes. Induction of brown adipocytes in white fat depots of rodents was first investigated in the 1980s and 1990s by cold or $\beta$-adrenergic receptor agonist treatment [33-35]. Although inducible brown adipocytes have thermogenic function like classical brown adipocytes, this population of adipocytes has a distinct developmental origin from classical brown adipocytes [5,6,48]. Notably, the functional brite adipocytes are present and can be induced in both infant and adult humans, thus the induction of active brite adipocytes in humans may be a promising strategy for preventing and treating obesity-related disorders. As classical brown adipocytes, brite fat cells also have thermogenic genes e.g. Ucp1, Ppara, and Pgcla [26,28,32,49,50], but they share a common molecular signature named Hoxc8 with white adipocytes [1]. However, inducible brown adipocytes also have their own molecular markers such as homeobox C9 (Hoxc9) and tumor necrosis factor receptor superfamily member 9 (CD137) [29,47,51].

Inducible brown adipocytes share the thermogenic function with classical brown fat cells, but have the same developmental origin as white adipocytes [3-7,52]. Classical brown adipocytes share their origin from myf $5^{+}$myotomal precursors with muscle cells $[3,4]$, while brite and white adipocytes derive from myf5 precursors [5-7]. In 2014, Jonathan et al showed that inducible brown adipocytes may come from a smooth muscle-like origin as the smooth muscle-like cells developed into brite adipocytes in vivo under cold stimulation and differentiated into brite cells in the presence of PR domain containing 16 (PRDM16) in vitro [52].

\section{The expression of OPA1 in adipocytes}

OPA1 is found to be expressed in both white and brown adipocytes at the mRNA and protein levels in vivo and in vitro [53-62] (Table 1). However, there are higher levels of OPA1 protein in brown versus white fat of mice with normal body weight [53]. It is known that OPA1 locates on the inner membrane of mitochondria facing the intermembranous space to regulate mitochondrial morphology. However, recently this protein has also been found on the lipid droplets of white adipocytes [53,63] (Fig. 2A). The pool of OPA1 located to lipid droplets was shown to be involved in the regulation of lipolytic function of adipocytes by Pidoux et al in 2011 [53]. Both OPA1 and the lipid droplet coat protein perilipin are increased during the differentiation of white adipocytes [53], which means that lipid accumulation and 
expression of OPA1 occur concomitantly in white fat cells. This in vitro observation is supported by a dog model of diet-induced obesity in vivo, in which the expansion of white fat during obesity development is accompanied with the increased expression of OPA1 in adipose tissues [55]. There are at least two different forms of OPA1, long (L-OPA1, 100 KDa) and short (S-OPA1, 85 Kda) forms in mouse adipocytes in the basal condition [54,64].

The expression of OPA1 and mitochondrial genes in adipocytes are regulated by transcriptional factors, hormones, enzymes, tumor suppressor proteins, cytokines and even food constituents and medication [54,55,57-60,64-69] (Fig. 2B). We know that transcriptional factors such as the forkhead box protein C2 (FOXC2) and peroxisome proliferator-activated receptors (PPARs) control the genes of mitochondrial morphology and biogenesis in adipocytes [56-58]. In a primary culture of brown adipocytes, overexpression of FOXC2 increases the expression of both mitochondrial fusion genes (Opal, Mitofusin1 and 2 (Mfn1 and Mfn2)) and brown-fat-related-markers (Prdm16 and DIO2 deiodinase (Dio2)) [57]. In adipocytes differentiated from 3T3-L1 or C3H/10T1/2 cells, the stimulation of PPAR $\gamma$ by its agonist rosiglitazone elevates mRNA levels of Opal, mitofilin and the transcription factors/cofactors of mitochondrial genes such as Pgc-1 (Ppargclb) and estrogen related receptor alpha (Err $\alpha)$ [58]. The regulatory effect of PPAR $\gamma$ on adipose OPA1 was confirmed by Anusree et al in 2015 [62], as their findings showed that punicic acid (PA), a poly unsaturated fatty acid with PPAR $\gamma$ agonist properties [70,71], blocked the inhibitory effect of tumor necrosis factor- $\alpha$ (TNF- $\alpha$ ) on OPA1 expression in 3T3-L1 adipocytes [62].

Some hormones including sex hormones and catecholamines have effects on the expression of OPA1 in adipocytes [59,64]. For example, 17- $\beta$ estradiol, increases adipogenesis and mitochondrial proliferation in 3T3-L1, and enhances the mRNA expression of Opal and dynamin related protein 1 (Drpl) in differentiated adipocytes; while testosterone has the opposite effects [59]. Ghrelin is an orexigenic hormone, which has been known to increase lipid accumulation in white fat and appetite, but that decreases norepinephrine (NE) release from brown adipocytes and therefore promotes obesity [60,68,7276]. Mice lacking Ghrelin ( $\mathrm{Ghsr}^{-/-}$mice) has increased mRNA expression of Opal as well as the genes of thermogenesis and mitochondria in adipose tissues [68]. Additionally, a combined treatment of NE and palmitate $(\mathrm{P})$ induces OPA1 cleavage resulting in decreasing L-OPA1 but elevating S-OPA1 in brown adipocytes [64].

Master regulators of OPA1 expression in adipocytes also include tumor suppressor proteins, proteolytic enzymes and cytokines [60,69]. Specifically, knockout of the retinoblastoma protein (pRb), a tumor suppressor, in adipose tissues results in higher expression of Opal and brown genes such as Ucpl and 
Pgcla in white fat depots [69]. In contrast, loss of the metalloendopeptidase OMA1 (OMA1), a proteolytic enzyme located in the inner membrane of mitochondria [60], leads to decreasing expression of OPA1 at both mRNA and protein levels in brown fat cells of mice [60]. This decrease in OPA1 expression in brown adipocytes is also found in mice lacking the non-receptor tyrosine-protein kinase TYK2 (Tyk2), an enzyme that belong to the Jak kinase family members [67]. In 3T3-L1 adipocytes, TNF- $\alpha$ suppresses the expression levels of total Opal and Pgcl $\alpha[62,65]$. Moreover, some chemicals which have browning effects on white adipocytes such as fucoxanthin [77] and exenatide [78] can promote OPA1 expression in white fat depots of animals [66,79].

\section{The function of OPA1 in lipolysis of adipocytes}

Lipolysis, the hydrolysis of triglycerides into glycerol and free fatty acids, is a specific function of adipocytes including white, brite and brown cells [32,80,81]. Physiologically, this process is mainly induced by $\beta$-adrenoceptor ( $\beta$-AR) stimulation of catecholamines such as epinephrine and norepinephrine; these hormones are released in response to cold exposure [32]. The catecholamine triggering of G proteincoupled receptors (7TM receptors) activates adenylate cyclase (adenylyl cyclase) followed by an increase in intracellular cAMP levels which activates protein kinase A (PKA) [80-82]. The phosphorylation of PKA subsequently activates lipases such as adipose triglyceride lipase (ATGL), lipoprotein lipase (LPL) and hormone-sensitive lipase (HSL) to stimulate lipolysis in adipocytes [32,80-83].

The abundant expression of OPA1 in functional adipocytes [53-60], especially the increase of its level during lipid accumulation in adipocytes both in vitro and in vivo [53,55], shows the potential involvement of OPA1 in lipid metabolism of adipocytes. The first report on OPA1 function in adipose lipolysis came from a new discovery of OPA1 location on lipid droplets by Pidoux and colleagues in 2011 [53,84] (Table 2). In white adipocytes differentiated from the 3T3-L1 cell line, a perfect overlap between OPA1 and a specific lipid-droplet-protein (perilipin) was found [53]. This analysis was triggered by the finding that perilipin phosphorylation depended on an anchored pool of PKA bound to an unidentified A-kinase anchoring protein (AKAP). By a combination of proteomic analysis of lipid droplets, a bioinformatic search for putative PKA binding sites in AKAPs and biochemical approaches to analyze PKA-AKAP interactions, OPA1 was identified as an AKAP on lipid droplets. Further investigation of OPA1 function in relation to lipolysis in adipocytes revealed that OPA1 is the AKAP responsible for perilipin phosphorylation to induce lipolysis in response to adrenergic stimuli (Fig. 3) [53,84].

\section{The function of OPA1 in regulation of mitochrondial morphology and thermogenesis of adipocytes}


OPA1 is known as a regulator of mitochondrial fusion [86-88]. In mitochondria, OPA1 and mitofusins (Mfns such as Mfn1 and Mfn2) work together to promote fusion, whereas mitochondrial fission 1 protein (Fis1) and Drp1 are essential in mitochondrial fission [89]. For this reason, efforts have focussed on investigating the role of OPA1 in mitochondria also in adipocytes $[54,57,58,62,67,68]$ whereas work in the role of OPA1 on lipid droplets in much more limited [53] (Table 2). Among investigations of OPA1 in adipocytes, most studies have examined mitochondria of classical brown cells, probably because of the abundant mitochondria in brown fat cells connected to their thermogenic function [33,57,90-98].

The high expression of Opal and thermogenic genes (Ucpl, Cidea, Pgcla and Ppara) in brown adipocytes or brown fat depots $[53,54,57,58]$ suggests its involvement in thermogenic function. In fact, upregulation or activation of factors controlling OPA1 expression such as FOXC2 and PPAR $\gamma$ results in alteration of brown adipocyte heat production [57,58]. Furthermore, it has been known that FOXC2 enhances thermogenic function by increasing PKA signaling in brown adipose tissues [56].

Non shivering-thermogenesis is a unique function of brown adipocytes, enabled by uncoupling protein 1 (Ucp1) in mitochondria $[2,75,99,100]$. The resulting heat production in Ucp1-expressing-adipocytes is activated by cold exposure, catecholamines and thyroid hormones [101]. Interestingly, NE and other catecholamines can induce lipolysis both in brown and white fat cells, but they preferentially stimulate thermogenesis in brown adipocytes [32]. In brown adipocyte tissues, either cold stress or the combined action of NE and palmitate (P) induce OPA1 cleavage [54,64] and a resulting increase in both mitochondrial content and thermogenesis [75]. Notably, the energy expenditure and S-OPA1 formation of brown adipocytes induced by the combined NE and P stimulation go together with Drp1-mediated fission and upstream of depolarization in mitochondria [64]. These findings indicate that in classical brown adipocytes the mitochondrial fission and OPA1 cleavage amplifies the thermogenic function [64] (Fig. 4A).

The relation between OPA1 and energy expenditure in brown adipocytes has been investigated [54,67,68]. Fatty acid oxidation is required for thermogenesis of brown fat depots [102], and the loss of OPA1 activities impairs the $\beta$-oxidation of brown adipocytes [54]. Primary brown adipocytes treated with OPA1 siRNA had around a $25 \%$ lower rate of palmitate oxidation compared to control adipocytes [54]. This result demonstrates the effect of OPA1 on the thermogenic function of brown adipocytes. In addition, some models have showed the coordinated expression and/or activities of OPA1 and thermogenic genes in brown adipocytes $[54,67,68]$. Oma $1^{-{ }_{-}}$and Tyk $2^{-{ }^{-}}$mice have suppressed expression of OPA1 and energy expenditure in brown fat depots [54,67], whereas $\mathrm{Ghsr}^{-/-}$mice have an increase in mRNA expression of both Opal and Ucpl [68]. OPA1 processing and mitochondrial fusion are regulated 
by m-AAA protease isoenzymes and OMA1 [60], therefore brown adipose tissues of Oma1 ${ }^{-1-}$ mice display lower expression of mitochondrial dynamic genes such as Opal, Mfn2 and Drpl together with a decrease in mRNA levels of $\beta$-oxidation genes including very long-chain acyl-CoA dehydrogenase (Vlcad) and carnitine palmitoyltransferase I (Cpt1b) [54]. Similar results were found in Tyk $2^{-/-}$mice [67]. Mice lacking Tyk2 have defects in thermogenesis and OPA1 expression in brown adipose tissues [67]. The impaired function of brown fat cells in Tyk $2^{-/-}$mice is evident from the suppression of mRNA and protein levels of thermogenic markers such Ucp1, Prdm16, Cidea and Ppara, resulting in development of obesity [67]. Furthermore, brown fat tissues of Tyk2 KO mice do not respond to cold exposure. However, the function of Tyk $2^{-/-}$brown adipocytes is restored upon reexpressing Tyk2 [67]. In contrast, brown fat of mice lacking ghrelin has significantly higher mRNA expression of Opal, Mfns, Drpl and Fis 1 compared to brown fat of wild type mice; this elevation of mitochondrial dynamic genes is coupled with an increase in the expression and phosphorylation of HSL and PKA protein in brown adipose tissues [68].

In inducible brown adipocytes mitochondrial fission events are not connected with thermogenesis. Thiazolidine-induced-adipocytes from the 3T3-L1 cell line have a decrease in the expression of total OPA1 and the thermogenic gene Pgcla, but show increased mitochondrial fragmentation upon stimulation with TNF- $\alpha[62,65]$. TNF- $\alpha$ induction mitochondrial dysfunction in inducible brown adipocytes is also indicated by its suppression in the genes of mitochondrial biogenesis (cytochrome $c$ oxidase subunit I (Cox-1), nuclear respiratory factor 1 (Nrf1), transcription factor A mitochondrial (Tfam) and mitochondrial DNA (mtDNA)) [62]. This is supported by experiments of PA treatment in vitro [62] and fucoxanthin supplementation in vivo [79]; PA incrases the OPA1 levels, glucose uptake, mitochondrial biogenesis and energy expenditure in 3T3-L1 adipocytes in vitro, but decreases the expression of Fis1 [62]. In vivo diet-induced obesity (DIO) mice receiving fucoxanthin-supplemented food for 5 weeks have higher levels of OPA1 and other fusion proteins together with higher expression of thermogenic genes such as Ucpl and Pgcla in white fat depots. Fucoxanthin, an edible seaweed carotenoid, has been previously reported to have browning effects on white fat depots of mice [77]. In rats on high fat diet, injection of exenatide - a glucagon-like peptide-1 (GLP-1) receptor agonist increases the expression of $\mathrm{Hsl}$, Opal and other mitochondrial dynamic genes in WAT [66]. Therefore, exenatide enhances lipid use in adipose tissue to improve hepatic steatosis [66]. Furthermore, as a mitochondrial protein, OPA1 may also be involved in the browning of white adipose tissues [69]. In a mouse model, specific knockout of the retinoblastoma (pRb) protein in adipose tissues results in significant expression of Opal and brown genes such as Ucpl and Pgcla in white fat depots [69]. This deficiency of adipose $\mathrm{pRb}$ also increases energy expenditure to protect animals against diabesity [69]. Together these findings suggest that the thermogenesis of brown adipocytes induced in white fat depots is at least partially 
regulated by OPA1, and the relationship between the thermogenic program and OPA1 seems to be linked to fusion rather than fission event of mitochondria (Fig. 4B).

\section{Perspectives}

The available data regarding OPA1 and adipocytes indicates that OPA1 is present in all three types of fat cells - white, inducible and classical brown adipocytes. OPA1 is present in the inner membrane of fat cell mitochondria, but there is also evidence showing its localization to lipid droplets of adipocytes. Functional studies of OPA1 effects on lipid metabolism reveal the connection of OPA1 location and its functions in thermogenesis and lipolysis of adipocytes.

In classical brown adipocytes, OPA1 in the mitochondrial inner-membrane contributes to regulation of mitochondrial morphology and thermogenic function. Consequently, the loss of OPA1 leads to dysregulation of mitochondrial morphology and impairment in heat production of brown adipocytes. It is clear that the thermogenesis of classical brown fat cells is increased by fission events and OPA1 cleavage in mitochondria induced by NE. Furthermore, free fatty acids (FFAs) released from lipid droplets in lipolysis stimulated by NE induces mitochondrial depolarization which is required to convert OPA1-L to OPA1-S form in classical brown adipocytes. However, in inducible brown adipocytes indirect data indicate that the increase of OPA1 activity is paralleled by elevation of thermogenic function, but these increases seems to be accompanied with fusion not fission events.

In white adipocytes, OPA1 protein on lipid droplets (LD) functions as an AKAP to facilitate adrenergic stimulation of lipolysis. Catecholamines thus activate PKA bound to OPA1 located on the surface of lipid droplets and induce phosphorylation of perilipin, the gatekeeper that controls lipid hydrolysis. These findings provided an important new role of OPA1 in lipid metabolism which has led to several interesting questions that need to be addressed such as: (i) Does OPA1 also locate on LDs and stimulate lipolysis in inducible brown adipocytes which has characteristics of both white and classical brown adipocytes with both quite big lipid droplets and high amounts of mitochondria?; (ii) What are the roles of OPA1 in thermogenic function of inducible brown fat cells?; and (iii) Does OPA1 also function as an AKAP and mediate adrenergic control of thermogenesis in brown cells?

Interestingly, previous reports have showed that the phosphorylation of perilipin is required for both lipolysis and thermogenesis of brown adipose tissues [103] and that perilipin 5 via its C-terminal region contributes to recruiting mitochondria to a juxtaposition versus lipid droplets in cardiac myocytes [104]. Furthermore, the overexpression of perilipin in white adipocyte tissues induces brown fat cells [105] which contribute to protecting mice against diet-induced obesity [106]. Thus, another open question (iv) 
is whether OPA1 can connect and coordinate lipolysis and thermogenesis in inducible brown adipocytes

to control lipid metabolism? Addressing these questions will advance understanding of the interaction between lipid droplets and mitochondria.

\section{References}

1. Wilting R, Yanover E, Heideman M, Jacobs H, Horner J, van der Torre J, DePinho R, Dannenberg J. Overlapping functions of Hdac1 and Hdac2 in cell cycle regulation and haematopoiesis. EMBO J 2010; 29: 2586 - 2597

2. Cannon B, Nedergaard J. Brown Adipose Tissue: Function and Physiological Significance. Physiological Reviews 2004; 84: 277-359

3. Atit R, Sgaier SK, Mohamed OA, Taketo MM, Dufort D, Joyner AL, Niswander L, Conlon RA. $\beta$ catenin activation is necessary and sufficient to specify the dorsal dermal fate in the mouse. Developmental Biology 2006; 296: 164-176

4. Timmons JA, Wennmalm K, Larsson O, Walden TB, Lassmann T, Petrovic N, Hamilton DL, Gimeno RE, Wahlestedt C, Baar K, Nedergaard J, Cannon B. Myogenic gene expression signature establishes that brown and white adipocytes originate from distinct cell lineages. Proceedings of the National Academy of Sciences 2007; 104: 4401-4406

5. Petrovic N, Walden TB, Shabalina IG, Timmons JA, Cannon B, Nedergaard J. Chronic Peroxisome Proliferator-activated Receptor $\gamma$ (PPAR $\gamma$ ) Activation of Epididymally Derived White Adipocyte Cultures Reveals a Population of Thermogenically Competent, UCP1-containing Adipocytes Molecularly Distinct from Classic Brown Adipocytes. Journal of Biological Chemistry 2010; 285: 7153-7164

6. Seale P, Bjork B, Yang W, Kajimura S, Chin S, Kuang S, Scime A, Devarakonda S, Conroe HM, Erdjument-Bromage H, Tempst P, Rudnicki MA, Beier DR, Spiegelman BM. PRDM16 controls a brown fat/skeletal muscle switch. Nature 2008; 454: 961-967

7. Rosenwald M, Wolfrum C. The origin and definition of brite versus white and classical brown adipocytes. Adipocyte 2014; 3: 4-9

8. Gesta S, Tseng Y-H, Kahn CR. Developmental Origin of Fat: Tracking Obesity to Its Source. Cell 2007; 131: 242-256

9. Bjørndal B,, Burri L, Staalesen V, Skorve J, Berge RK. Different Adipose Depots: Their Role in the Development of Metabolic Syndrome and Mitochondrial Response to Hypolipidemic Agents. Journal of Obesity 2011; 15 pages

10.Koza RA, Nikonova L, Hogan J, Rim J-S, Mendoza T, Faulk C, Skaf J, Kozak LP. Changes in Gene Expression Foreshadow Diet-Induced Obesity in Genetically Identical Mice. PLoS Genet 2006; 2: e81

11.Nikonova L, Koza RA, Mendoza T, Chao P-M, Curley JP, Kozak LP. Mesoderm-specific transcript is associated with fat mass expansion in response to a positive energy balance. The FASEB Journal 2008; 22: 3925-3937

12.Kozak LP, Newman S, Chao P-M, Mendoza T, Koza RA. The Early Nutritional Environment of Mice Determines the Capacity for Adipose Tissue Expansion by Modulating Genes of Caveolae Structure. PLoS ONE 2010; 5: e11015

13. Mori H, Prestwich TC, Reid MA, Longo KA, Gerin I, Cawthorn WP, Susulic VS, Krishnan V, Greenfield A, MacDougald OA. Secreted frizzled-related protein 5 suppresses adipocyte mitochondrial metabolism through WNT inhibition. The Journal of Clinical Investigation 2012; 122(7): 2405-2416

14.Jura M, Jarosławska J, Chu DT, Kozak LP. Mest and Sfrp5 are biomarkers for healthy adipose tissue. Biochimie 2016; 124: 124-133

15. Chu D-T, Malinowska E, Gawronska-Kozak B, Kozak LP. Expression of Adipocyte Biomarkers in a Primary Cell Culture Models Reflects Preweaning Adipobiology. Journal of Biological Chemistry 2014; 289: 18478-18488 
16.Kozak LP. Brown Fat and the Myth of Diet-Induced Thermogenesis. Cell metabolism 2010; 11: 263267

17. Cypess AM, Lehman S, Williams G, Tal I, Rodman D, Goldfine AB, Kuo FC, Palmer EL, Tseng Y-H, Doria A, Kolodny GM, Kahn CR. Identification and Importance of Brown Adipose Tissue in Adult Humans. New England Journal of Medicine 2009; 360: 1509-1517

18. Saito M, Okamatsu-Ogura Y, Matsushita M, Watanabe K, Yoneshiro T, Nio-Kobayashi J, Iwanaga T, Miyagawa M, Kameya T, Nakada K, Kawai Y, Tsujisaki M. High Incidence of Metabolically Active Brown Adipose Tissue in Healthy Adult Humans: Effects of Cold Exposure and Adiposity. Diabetes 2009; 58: 1526-1531

19.van Marken Lichtenbelt WD, Vanhommerig JW, Smulders NM, Drossaerts JMAFL, Kemerink GJ, Bouvy ND, Schrauwen P, Teule GJJ. Cold-Activated Brown Adipose Tissue in Healthy Men. New England Journal of Medicine 2009; 360: 1500-1508

20.Virtanen KA, Lidell ME, Orava J, Heglind M, Westergren R, Niemi T, Taittonen M, Laine J, Savisto N-J, Enerbäck S, Nuutila P. Functional Brown Adipose Tissue in Healthy Adults. New England Journal of Medicine 2009; 360: 1518-1525

21.Zingaretti MC, Crosta F, Vitali A, Guerrieri M, Frontini A, Cannon B, Nedergaard J, Cinti S. The presence of UCP1 demonstrates that metabolically active adipose tissue in the neck of adult humans truly represents brown adipose tissue. The FASEB Journal 2009; 23: 3113-3120

22.Nagano G, Ohno H, Oki K, Kobuke K, Shiwa T, Yoneda M, Kohno N. Activation of Classical Brown Adipocytes in the Adult Human Perirenal Depot Is Highly Correlated with PRDM16-EHMT1 Complex Expression. PLoS ONE 2015; 10: e0122584

23.Lidell ME, Betz MJ, Leinhard OD, Heglind M, Elander L, Slawik M, Mussack T, Nilsson D, Romu T, Nuutila P, Virtanen KA, Beuschlein F, Persson A, Borga M, Enerback S. Evidence for two types of brown adipose tissue in humans. Nat Med 2013; 19: 631-634

24.Harms M, Seale P. Brown and beige fat: development, function and therapeutic potential. Nat Med 2013; 19: 1252-1263

25.Heaton JM. The distribution of brown adipose tissue in the human. Journal of Anatomy 1972; 112: 35 39

26.Jespersen Naja Z, Larsen Therese J, Peijs L, Daugaard S, Homøe P, Loft A, de Jong J, Mathur N, Cannon B, Nedergaard J, Pedersen Bente K, Møller K, Scheele C. A Classical Brown Adipose Tissue mRNA Signature Partly Overlaps with Brite in the Supraclavicular Region of Adult Humans. Cell metabolism 2013; 17: 798-805

27. Shabalina IG, Jacobsson A, Cannon B, Nedergaard J. Native UCP1 Displays Simple Competitive Kinetics between the Regulators Purine Nucleotides and Fatty Acids. Journal of Biological Chemistry 2004; 279: 38236-38248

28. Sharp LZ, Shinoda K, Ohno H, Scheel DW, Tomoda E, Ruiz L, Hu H, Wang L, Pavlova Z, Gilsanz V, Kajimura S. Human BAT Possesses Molecular Signatures That Resemble Beige/Brite Cells. PLoS ONE 2012; 7: e49452

29. Waldén TB, Hansen IR, Timmons JA, Cannon B, Nedergaard J. Recruited vs. nonrecruited molecular signatures of brown, "brite," and white adipose tissues. American Journal of Physiology Endocrinology And Metabolism 2011; 302: E19-E31

30.Wu J, Cohen P, Spiegelman BM. Adaptive thermogenesis in adipocytes: Is beige the new brown? Genes \& Development 2013; 27: 234-250

31.Fisher fM, Kleiner S, Douris N, Fox EC, Mepani RJ, Verdeguer F, Wu J, Kharitonenkov A, Flier JS, Maratos-Flier E, Spiegelman BM. FGF21 regulates PGC-1 $\alpha$ and browning of white adipose tissues in adaptive thermogenesis. Genes \& Development 2012; 26: 271-281

32. Shinoda K, Ohyama K, Hasegawa Y, Chang H-Y, Ogura M, Sato A, Hong H, Hosono T, Sharp Louis Z, Scheel David W, Graham M, Ishihama Y, Kajimura S. Phosphoproteomics Identifies CK2 as a Negative Regulator of Beige Adipocyte Thermogenesis and Energy Expenditure. Cell Metabolism 2015; 22 (6): 997-1008 
33.Lonçar D, Afzelius BA, Cannon B. Epididymal white adipose tissue after cold stress in rats I. Nonmitochondrial changes. Journal of Ultrastructure and Molecular Structure Research 1988; 101: $109-122$

34.Guerra C, Koza RA, Yamashita H, Walsh K, Kozak LP. Emergence of brown adipocytes in white fat in mice is under genetic control. Effects on body weight and adiposity. The Journal of Clinical Investigation 1998; 102: 412-420

35.Himms-Hagen J, J. C, Danforth E, J. TD, Lang S. S, Waters B. L, H CT. Effect of CL-316,243, a thermogenic beta 3-agonist, on energy balance and brown and white adipose tissues in rats. American Journal of Physiology - Regulatory, Integrative and Comparative Physiology 1994; 266: R1371-R1382

36.Dong M, Yang X, Lim S, Cao Z, Honek J, Lu H, Zhang C, Seki T, Hosaka K, Wahlberg E, Yang J, Zhang L, Länne T, Sun B, Li X, Liu Y, Zhang Y, Cao Y. Cold Exposure Promotes Atherosclerotic Plaque Growth and Instability via UCP1-Dependent Lipolysis. Cell metabolism 2013; 18: 118-129

37.Elabd C, Chiellini C, Carmona M, Galitzky J, Cochet O, Petersen R, Pénicaud L, Kristiansen K, Bouloumié A, Casteilla L, Dani C, Ailhaud G, Amri E-Z. Human Multipotent Adipose-Derived Stem Cells Differentiate into Functional Brown Adipocytes. STEM CELLS 2009; 27: 2753-2760

38.Pardo R, Enguix N, Lasheras J, Feliu JE, Kralli A, Villena JA. Rosiglitazone-Induced Mitochondrial Biogenesis in White Adipose Tissue Is Independent of Peroxisome Proliferator-Activated Receptor $\gamma$ Coactivator-1 $\alpha$. PLoS ONE 2011; 6: e26989

39. Kozak UC, Kozak LP. Norepinephrine-dependent selection of brown adipocyte cell lines. Endocrinology 1994; 134: 906-913

40.Tvrdik P, Asadi A, Kozak LP, Nedergaard J, Cannon B, Jacobsson A. Cig30, a Mouse Member of a Novel Membrane Protein Gene Family, Is Involved in the Recruitment of Brown Adipose Tissue. J Biol Chem 1997; 272: 31738-31746

41.Bengtsson T, Redegren K, Strosberg AD, Nedergaard J, Cannon B. Down-regulation of $\beta 3$ Adrenoreceptor Gene Expression in Brown Fat Cells Is Transient and Recovery Is Dependent upon a Short-lived Protein Factor. Journal of Biological Chemistry 1996; 271: 33366-33375

42.Boon MR, van den Berg SAA, Wang Y, van den Bossche J, Karkampouna S, Bauwens M, De SaintHubert M, van der Horst G, Vukicevic S, de Winther MPJ, Havekes LM, Jukema JW, Tamsma JT, van der Pluijm G, van Dijk KW, Rensen PCN. BMP7 Activates Brown Adipose Tissue and Reduces Diet-Induced Obesity Only at Subthermoneutrality. PLoS ONE 2013; 8: e74083

43. Schulz TJ, Huang TL, Tran TT, Zhang H, Townsend KL, Shadrach JL, Cerletti M, McDougall LE, Giorgadze N, Tchkonia T, Schrier D, Falb D, Kirkland JL, Wagers AJ, Tseng Y-H. Identification of inducible brown adipocyte progenitors residing in skeletal muscle and white fat. Proceedings of the National Academy of Sciences 2011; 108: 143-148

44.Zhang H, Schulz TJ, Espinoza DO, Huang TL, Emanuelli B, Kristiansen K, Tseng Y-H. Cross Talk between Insulin and Bone Morphogenetic Protein Signaling Systems in Brown Adipogenesis. Molecular and Cellular Biology 2010; 30: 4224-4233

45.Lee P, Linderman Joyce D, Smith S, Brychta Robert J, Wang J, Idelson C, Perron Rachel M, Werner Charlotte D, Phan Giao Q, Kammula Udai S, Kebebew E, Pacak K, Chen Kong Y, Celi Francesco S. Irisin and FGF21 Are Cold-Induced Endocrine Activators of Brown Fat Function in Humans. Cell Metabolism; 19: 302-309

46.Wu J, Spiegelman BM. Irisin ERKs the Fat. Diabetes 2014; 63: 381-383

47. Bayindir I, Babaeikelishomi R, Kocanova S, Sousa IS, Lerch S, Hardt O, Wild S, Bosio A, Bystricky $\mathrm{K}$, Herzig S, Vegiopoulos A. Transcriptional pathways in cPGI2-induced adipocyte progenitor activation for browning. Frontiers in Endocrinology 2015; 6

48.Wu J, Boström P, Sparks Lauren M, Ye L, Choi Jang H, Giang A-H, Khandekar M, Virtanen Kirsi A, Nuutila P, Schaart G, Huang K, Tu H, van Marken Lichtenbelt Wouter D, Hoeks J, Enerbäck S, Schrauwen P, Spiegelman Bruce M. Beige Adipocytes Are a Distinct Type of Thermogenic Fat Cell in Mouse and Human. Cell 2012; 150: 366-376

49.Giralt M, Villarroya F. White, Brown, Beige/Brite: Different Adipose Cells for Different Functions? Endocrinology 2013; 154: 2992-3000 
50.Li Y, Bolze F, Fromme T, Klingenspor M. Intrinsic differences in BRITE adipogenesis of primary adipocytes from two different mouse strains. Biochimica et Biophysica Acta (BBA) - Molecular and Cell Biology of Lipids 2014; 1841: 1345-1352

51.Chu-Dinh T, Chu DT. 4-1BB and the Epigenetic Regulations of This Molecule. Medical Epigenetics 2014; $2: 80-85$

52.Long Jonathan Z, Svensson Katrin J, Tsai L, Zeng X, Roh Hyun C, Kong X, Rao Rajesh R, Lou J, Lokurkar I, Baur W, Castellot John J, Jr., Rosen Evan D, Spiegelman Bruce M. A Smooth MuscleLike Origin for Beige Adipocytes. Cell metabolism 2014; 19: 810-820

53.Pidoux G, Witczak O, Jarnæss E, Myrvold L, Urlaub H, Stokka AJ, Küntziger T, Taskén K. Optic atrophy 1 is an A-kinase anchoring protein on lipid droplets that mediates adrenergic control of lipolysis. The EMBO Journal 2011; 30: 4371-4386

54.Quirós PM, Ramsay AJ, Sala D, Fernández-Vizarra E, Rodríguez F, Peinado JR, Fernández-García MS, Vega JA, Enríquez JA, Zorzano A, López-Otín C. Loss of mitochondrial protease OMA1 alters processing of the GTPase OPA1 and causes obesity and defective thermogenesis in mice. The EMBO Journal 2012; 31: 2117-2133 55. Grant RW, Vester Boler BM, Ridge TK, Graves TK, Swanson KS. Adipose tissue transcriptome changes during obesity development in female dogs. Physiological Genomics 2011; 43: 295-307

56.Cederberg A, Grønning LM, Ahrén B, Taskén K, Carlsson P, Enerbäck S. FOXC2 Is a Winged Helix Gene that Counteracts Obesity, Hypertriglyceridemia, and Diet-Induced Insulin Resistance. Cell 2001; 106: $563-573$

57.Lidell ME, Seifert EL, Westergren R, Heglind M, Gowing A, Sukonina V, Arani Z, Itkonen P, Wallin S, Westberg F, Fernandez-Rodriguez J, Laakso M, Nilsson T, Peng X-R, Harper M-E, Enerbäck S. The Adipocyte-Expressed Forkhead Transcription Factor Foxc2 Regulates Metabolism Through Altered Mitochondrial Function. Diabetes 2011; 60: 427-435

58.Rong JX, Klein J-LD, Qiu Y, Xie M, Johnson JH, Waters KM, Zhang V, Kashatus JA, Remlinger KS, Bing N, Crosby RM, Jackson TK, Witherspoon SM, Moore JT, Ryan TE, Neill SD, Strum JC. Rosiglitazone Induces Mitochondrial Biogenesis in Differentiated Murine 3T3-L1 and C3H/10T1/2 Adipocytes. PPAR Research 2011; 11

59.Capllonch-Amer G, Lladó I, Proenza AM, García-Palmer FJ, Gianotti M. Opposite effects of 17- $\beta$ estradiol and testosterone on mitochondrial biogenesis and adiponectin synthesis in white adipocytes. Journal of Molecular Endocrinology 2014; 52: 203-214

60. Miegueu P, St Pierre D, Broglio F, Cianflone K. Effect of desacyl ghrelin, obestatin and related peptides on triglyceride storage, metabolism and GHSR signaling in 3T3-L1 adipocytes. Journal of Cellular Biochemistry 2011; 112: 704-714

61. Wang Y, Katayama A, Terami T, Han X, Nunoue T, Zhang D, Teshigawara S, Eguchi J, Nakatsuka A, Murakami K, Ogawa D, Furuta Y, Makino H, Wada J. Translocase of inner mitochondrial membrane 44 alters the mitochondrial fusion and fission dynamics and protects from type 2 diabetes. Metabolism 2015; 64: 677-688

62. Anusree SS, Nisha VM, Priyanka A, Raghu KG. Insulin resistance by TNF- $\alpha$ is associated with mitochondrial dysfunction in 3T3-L1 adipocytes and is ameliorated by punicic acid, a PPAR $\gamma$ agonist. Molecular and Cellular Endocrinology 2015; 413: 120-128

63. Kita T, Nishida H, Shibata H, Niimi S, Higuti T, Arakaki N. Possible Role of Mitochondrial Remodelling on Cellular Triacylglycerol Accumulation. Journal of Biochemistry 2009; 146: 787-796

64.Wikstrom JD, Mahdaviani K, Liesa M, Sereda SB, Si Y, Las G, Twig G, Petrovic N, Zingaretti C, Graham A, Cinti S, Corkey BE, Cannon B, Nedergaard J, Shirihai OS. Hormone-induced mitochondrial fission is utilized by brown adipocytes as an amplification pathway for energy expenditure. The EMBO Journal 2014; 33: 418-436

65.Hahn WS, Kuzmicic J, Burrill JS, Donoghue MA, Foncea R, Jensen MD, Lavandero S, Arriaga EA, Bernlohr DA. Proinflammatory cytokines differentially regulate adipocyte mitochondrial metabolism, oxidative stress, and dynamics. American Journal of Physiology - Endocrinology And Metabolism 2014; 306: E1033-E1045 
66.Kosuke Tanaka, Yuko Masaki, Masatake Tanaka, Masayuki Miyazaki, Munechika Enjoji, Makoto Nakamuta, Masaki Kato, Masatoshi Nomura, Toyoshi Inoguchi, Kazuhiro Kotoh, Takayanagi. R. Exenatide improves hepatic steatosis by enhancing lipid use in adipose tissue in nondiabetic rats. World J Gastroenterol 2014; 20: 2653-2663

67.Derecka M, Gornicka A, Koralov Sergei B, Szczepanek K, Morgan M, Raje V, Sisler J, Zhang Q, Otero D, Cichy J, Rajewsky K, Shimoda K, Poli V, Strobl B, Pellegrini S, Harris Thurl E, Seale P, Russell Aaron P, McAinch Andrew J, O’Brien Paul E, Keller Susanna R, Croniger Colleen M, Kordula T, Larner Andrew C. Tyk2 and Stat3 Regulate Brown Adipose Tissue Differentiation and Obesity. Cell Metabolism 2012; 16: 814-824

68.Ligen Lin, Jong Han Lee, Odelia Y. N. Bongmba, Xiaojun Ma, Xiongwei Zhu, David Sheikh-Hamad, Sun Y. The suppression of ghrelin signaling mitigates age-associated thermogenic impairment. AGING 2014; Vol 6: 1019-1032

69.Dali-Youcef N, Mataki C, Coste A, Messaddeq N, Giroud S, Blanc S, Koehl C, Champy M-F, Chambon P, Fajas L, Metzger D, Schoonjans K, Auwerx J. Adipose tissue-specific inactivation of the retinoblastoma protein protects against diabesity because of increased energy expenditure. Proceedings of the National Academy of Sciences 2007; 104: 10703-10708

70.Hontecillas R, O'Shea M, Einerhand A, Diguardo M, Bassaganya-Riera J. Activation of PPAR $\gamma$ and $\alpha$ by Punicic Acid Ameliorates Glucose Tolerance and Suppresses Obesity-Related Inflammation. Journal of the American College of Nutrition 2009; 28: 184-195

71.Bassaganya-Riera J, DiGuardo M, Climent M, Vives C, Carbo A, Jouni ZE, Einerhand AWC, O'Shea M, Hontecillas R. Activation of PPAR $\gamma$ and $\delta$ by dietary punicic acid ameliorates intestinal inflammation in mice. British Journal of Nutrition 2011; 106: 878-886

72.Kojima M, Hosoda H, Date Y, Nakazato M, Matsuo H, Kangawa K. Ghrelin is a growth-hormonereleasing acylated peptide from stomach. Nature 1999; 402: 656-660

73.Tschop M, Smiley DL, Heiman ML. Ghrelin induces adiposity in rodents. Nature 2000; 407: 908-913

74. Shimbara T, Mondal MS, Kawagoe T, Toshinai K, Koda S, Yamaguchi H, Date Y, Nakazato M. Central administration of ghrelin preferentially enhances fat ingestion. Neuroscience Letters 2004; 369: 75-79

75.Rodriguez A, Gomez-Ambrosi J, Catalan V, Gil MJ, Becerril S, Sainz N, Silva C, Salvador J, Colina I, Fruhbeck G. Acylated and desacyl ghrelin stimulate lipid accumulation in human visceral adipocytes. Int J Obes 2009; 33: 541-552

76. Mano-Otagiri A, Ohata H, Iwasaki-Sekino A, Nemoto T, Shibasaki T. Ghrelin suppresses noradrenaline release in the brown adipose tissue of rats. Journal of Endocrinology 2009; 201: 341349

77. Maeda H, Hosokawa M, Sashima T, Funayama K, Miyashita K. Fucoxanthin from edible seaweed, Undaria pinnatifida, shows antiobesity effect through UCP1 expression in white adipose tissues. Biochemical and Biophysical Research Communications 2005; 332: 392-397

78. Beiroa D, Imbernon M, Gallego R, Senra A, Herranz D, Villarroya F, Serrano M, Fernø J, Salvador J, Escalada J, Dieguez C, Lopez M, Frühbeck G, Nogueiras R. GLP-1 Agonism Stimulates Brown Adipose Tissue Thermogenesis and Browning Through Hypothalamic AMPK. Diabetes 2014; 63: 3346-3358

79.Wu M-T, Chou H-N, Huang C-j. Dietary Fucoxanthin Increases Metabolic Rate and Upregulated mRNA Expressions of the PGC-1alpha Network, Mitochondrial Biogenesis and Fusion Genes in White Adipose Tissues of Mice. Marine Drugs 2014; 12: 964-982

80. Ahmadian M, Wang Y, Sul HS. Lipolysis in adipocytes. The International Journal of Biochemistry \& Cell Biology 2010; 42: 555-559

81.Duncan RE, Ahmadian M, Jaworski K, Sarkadi-Nagy E, Sul HS. Regulation of Lipolysis in Adipocytes. Annual Review of Nutrition 2007; 27: 79-101

82. Collins S. $\beta$-Adrenoceptor Signaling Networks in Adipocytes for Recruiting Stored Fat and Energy Expenditure. Frontiers in Endocrinology 2011; 2: 102 
83. McTernan PG, Harte AL, Anderson LA, Green A, Smith SA, Holder JC, Barnett AH, Eggo MC, Kumar S. Insulin and Rosiglitazone Regulation of Lipolysis and Lipogenesis in Human Adipose Tissue In Vitro. Diabetes 2002; 51: 1493-1498

84.Greenberg AS, Kraemer FB, Soni KG, Jedrychowski MP, Yan QW, Graham CE, Bowman TA, Mansur A. Lipid droplet meets a mitochondrial protein to regulate adipocyte lipolysis. The EMBO Journal 2011; 30: 4337-4339

85.Belenguer P, Pellegrini L. The dynamin GTPase OPA1: More than mitochondria? Biochimica et Biophysica Acta (BBA) - Molecular Cell Research 2013; 1833: 176-183

86. Olichon A, Guillou E, Delettre C, Landes T, Arnauné-Pelloquin L, Emorine LJ, Mils V, Daloyau M, Hamel C, Amati-Bonneau P, Bonneau D, Reynier P, Lenaers G, Belenguer P. Mitochondrial dynamics and disease, OPA1. Biochimica et Biophysica Acta (BBA) - Molecular Cell Research 2006; 1763: 500-509

87. Song Z, Chen H, Fiket M, Alexander C, Chan DC. OPA1 processing controls mitochondrial fusion and is regulated by mRNA splicing, membrane potential, and Yme1L. The Journal of Cell Biology 2007; 178: 749-755

88.Lee Y-j, Jeong S-Y, Karbowski M, Smith CL, Youle RJ. Roles of the Mammalian Mitochondrial Fission and Fusion Mediators Fis1, Drp1, and Opa1 in Apoptosis. Molecular Biology of the Cell 2004; 15: 5001-5011

89. Chen H, Chan DC. Emerging functions of mammalian mitochondrial fusion and fission. Human Molecular Genetics 2005; 14: R283-R289

90.Si Y, Palani S, Jayaraman A, Lee K. Effects of forced uncoupling protein 1 expression in 3T3-L1 cells on mitochondrial function and lipid metabolism. Journal of Lipid Research 2007; 48: 826-836

91.Hofmann WE, Liu X, Bearden CM, Harper M-E, Kozak LP. Effects of Genetic Background on Thermoregulation and Fatty Acid-induced Uncoupling of Mitochondria in UCP1-deficient Mice. Journal of Biological Chemistry 2001; 276: 12460-12465

92.Xue B, Rim J-S, Hogan JC, Coulter AA, Koza RA, Kozak LP. Genetic variability affects the development of brown adipocytes in white fat but not in interscapular brown fat. Journal of Lipid Research 2007; 48: 41-51

93.Fedorenko A, Lishko Polina V, Kirichok Y. Mechanism of Fatty-Acid-Dependent UCP1 Uncoupling in Brown Fat Mitochondria. Cell 2012; 151: 400-413

94.Fink BD, Herlein JA, Almind K, Cinti S, Kahn CR, Sivitz WI. Mitochondrial proton leak in obesityresistant and obesity-prone mice. American Journal of Physiology - Regulatory, Integrative and Comparative Physiology 2007; 293: R1773-R1780

95. Marette A, Bukowiecki LJ. Noradrenaline Stimulates Glucose-Transport in Rat Brown Adipocytes by Activating Thermogenesis - Evidence That Fatty-Acid Activation of Mitochondrial Respiration Enhances Glucose-Transport. Biochemical Journal 1991; 277: 119-124

96. Alvarez R, de Andrés J, Yubero P, Viñas O, Mampel T, Iglesias R, Giralt M, Villarroya F. A Novel Regulatory Pathway of Brown Fat Thermogenesis: RETINOIC ACID IS A TRANSCRIPTIONAL ACTIVATOR OF THE MITOCHONDRIAL UNCOUPLING PROTEIN GENE. Journal of Biological Chemistry 1995; 270: 5666-5673

97. Müller TD, Lee SJ, Jastroch M, Kabra D, Stemmer K, Aichler M, Abplanalp B, Ananthakrishnan G, Bhardwaj N, Collins S, Divanovic S, Endele M, Finan B, Gao Y, Habegger KM, Hembree J, Heppner KM, Hofmann S, Holland J, Küchler D, Kutschke M, Krishna R, Lehti M, Oelkrug R, Ottaway N, Perez-Tilve D, Raver C, Walch AK, Schriever SC, Speakman J, Tseng Y-H, Diaz-Meco M, Pfluger PT, Moscat J, Tschöp MH. p62 Links $\beta$-adrenergic input to mitochondrial function and thermogenesis. The Journal of Clinical Investigation 2013; 123: 469-478

98.Lee J-Y, Takahashi N, Yasubuchi M, Kim Y-I, Hashizaki H, Kim M-J, Sakamoto T, Goto T, Kawada T. Triiodothyronine induces UCP-1 expression and mitochondrial biogenesis in human adipocytes. American Journal of Physiology - Cell Physiolog 2012; 302: C463-C472 
99. Ye L, Wu J, Cohen P, Kazak L, Khandekar MJ, Jedrychowski MP, Zeng X, Gygi SP, Spiegelman BM. Fat cells directly sense temperature to activate thermogenesis. Proceedings of the National Academy of Sciences 2013; 110: 12480-12485

100. Himms-Hagen J. Nonshivering thermogenesis. Brain Research Bulletin 1984; 12: 151-160

101. Calvani R, Leeuwenburgh C, Marzetti E. Brown Adipose Tissue and the Cold War Against Obesity. Diabetes 2014; 63: 3998-4000

102. Lee J, Ellis Jessica M, Wolfgang Michael J. Adipose Fatty Acid Oxidation Is Required for Thermogenesis and Potentiates Oxidative Stress-Induced Inflammation. Cell Reports 2015; 10: 266279

103. Souza SC, Christoffolete MA, Ribeiro MO, Miyoshi H, Strissel KJ, Stancheva ZS, Rogers NH, D'Eon TM, Perfield JW, Imachi H, Obin MS, Bianco AC, Greenberg AS. Perilipin regulates the thermogenic actions of norepinephrine in brown adipose tissue. Journal of Lipid Research 2007; 48: $1273-1279$

104. Wang H, Sreenivasan U, Hu H, Saladino A, Polster BM, Lund LM, Gong D-w, Stanley WC, Sztalryd C. Perilipin 5, a lipid droplet-associated protein, provides physical and metabolic linkage to mitochondria. Journal of Lipid Research 2011; 52: 2159-2168

105. Sawada T, Miyoshi H, Shimada K, Suzuki A, Okamatsu-Ogura Y, Perfield JW, II, Kondo T, Nagai S, Shimizu C, Yoshioka N, Greenberg AS, Kimura K, Koike T. Perilipin Overexpression in White Adipose Tissue Induces a Brown Fat-Like Phenotype. PLoS ONE 2010; 5: e14006

106. Miyoshi H, Souza SC, Endo M, Sawada T, Perfield JW, Shimizu C, Stancheva Z, Nagai S, Strissel KJ, Yoshioka N, Obin MS, Koike T, Greenberg AS. Perilipin overexpression in mice protects against diet-induced obesity. Journal of Lipid Research 2010; 51: 975-982 
Table legends

Table 1. Expression of OPA1 in adipocytes

Table 2. Studies of OPA1 in lipolytic and thermogenic functions of adipocytes 


\section{Figure legends}

\section{Figure 1. Classification of adipocytes and their effects on obesity}

Figure 2. The expression of OPA1 in adipocytes and its regulators. A. In adipocytes, OPA1 locates to the inner membrane of mitochondria facing the intermembranous space or on the surface of lipid droplets. B. The expression of OPA1 in adipocytes is regulated by several factors including hormones, transcription factors, proteolytic enzymes, tumor suppressor proteins, and cytokines. Forkhead box protein C2 - FOXC2; Peroxisome proliferator-activated receptors - PPARs; Norepinephrine - NE; Metalloendopeptidase OMA1 - OMA1; Tumor necrosis factor- $\alpha$ - TNF- $\alpha$.

Figure 3. Function of OPA1 in facilitating adrenergic regulation of lipolysis of adipocytes. In adipocytes stimulated by isoproterenol, an adrenergic agonist, PKA bound to OPA1 located on the surface of lipid droplets (LD) is activated by cAMP signaling to phosphorylate perilipin. Subsequently, the perilipin allows access of lipases, start a lipolytic process to break down neutral fat to free fatty acids and glycerol.

Figure 4. Function of OPA1 in the thermogenesis of adipocytes. A. In classical brown adipocytes stimulated by catecholamines such as norepinephrine, OPA1 located in the inner membrane of mitochondria is involved in thermogenesis. The cleavage of OPA1 and mitochondrial fission amply the thermogenic function of these adipocytes. B. The function of OPA1 in mitochondrial morphology and thermogenesis of inducible brown adipocytes has not been fully understood, some indirect data show that thermogenic function of this type of fat cells is increased together with mitochondrial fusion under the stimulation of some reagents such as punicic acid, fucoxanthin and exenatide. 
Figure 1.

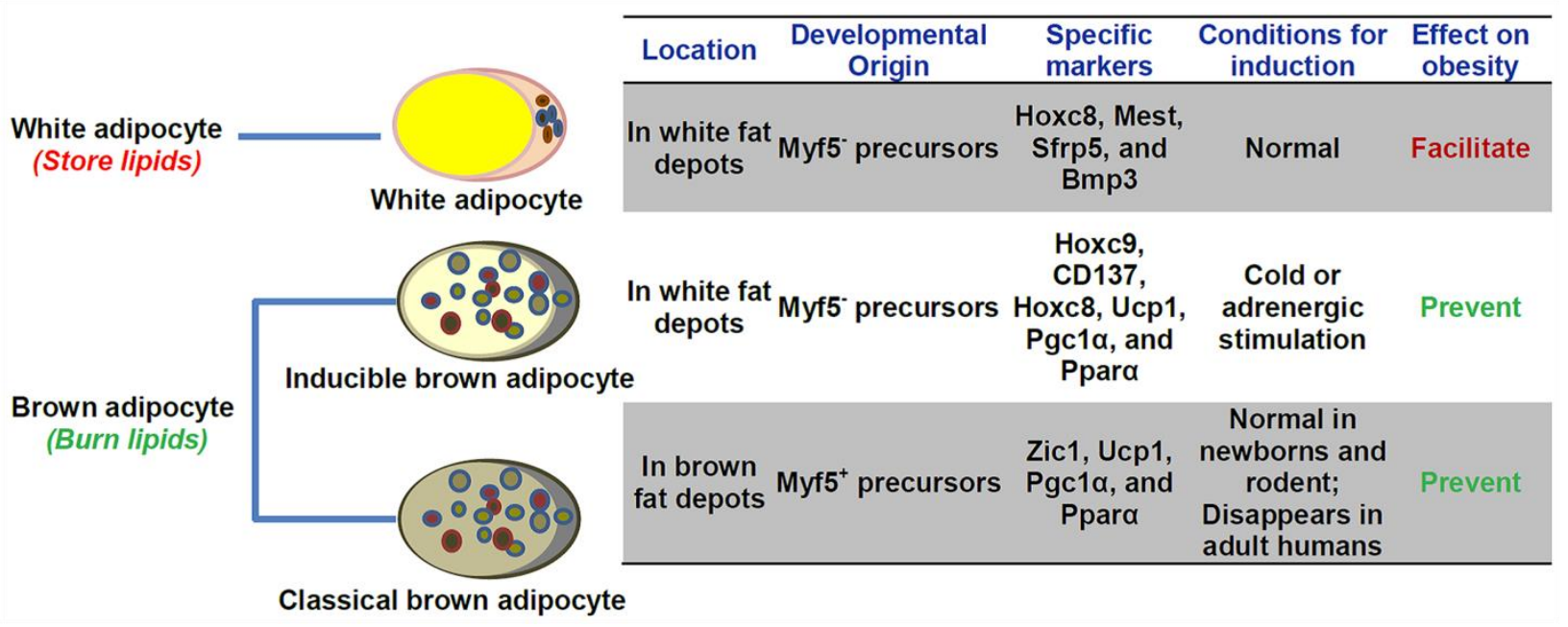


Figure 2.

A. The expression of OPA1 in adipocytes

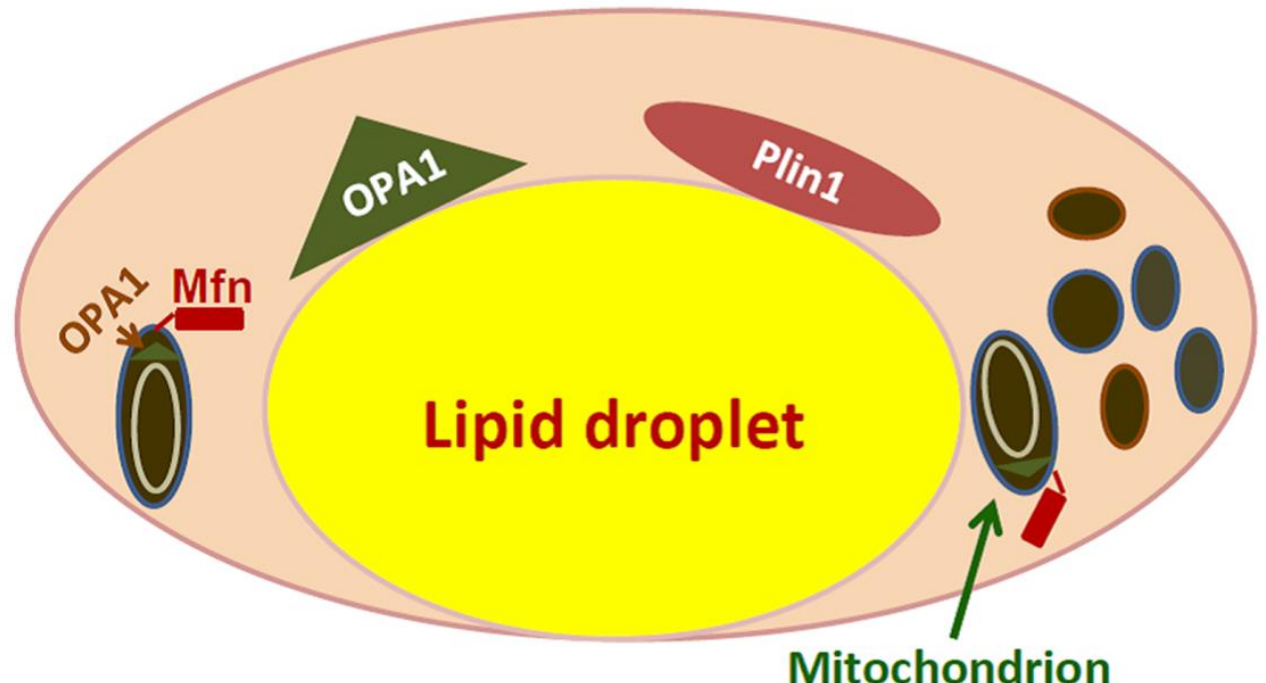

B. Factors regulate OPA1 expression in adipocytes

Up-regulators:

Down-regulators:

Transcriptional factors:

e.g. FOXC2 and PPARs

Hormones:

e.g. 17-6 estradiol and NE

Enzymes:

e.g. OMA1 and TYK2

Other chemicals:

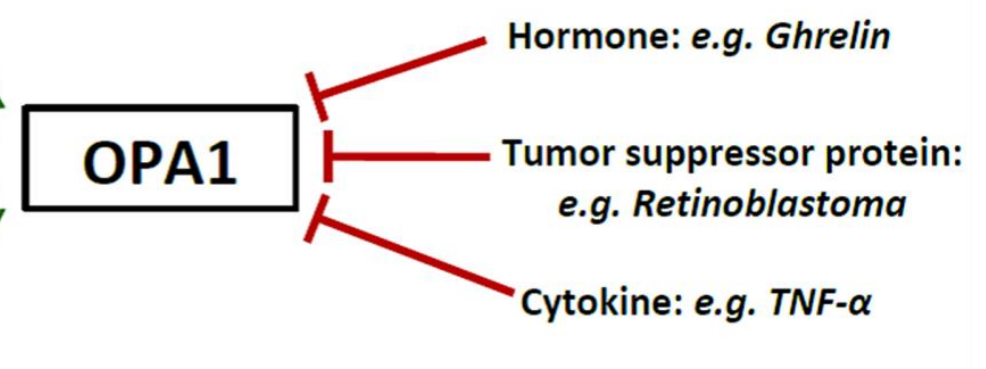

e.g. Fucoxanthin and Exenatide 
Figure 3.

Adrenergic agonist

(e.g. Isoproterenol)
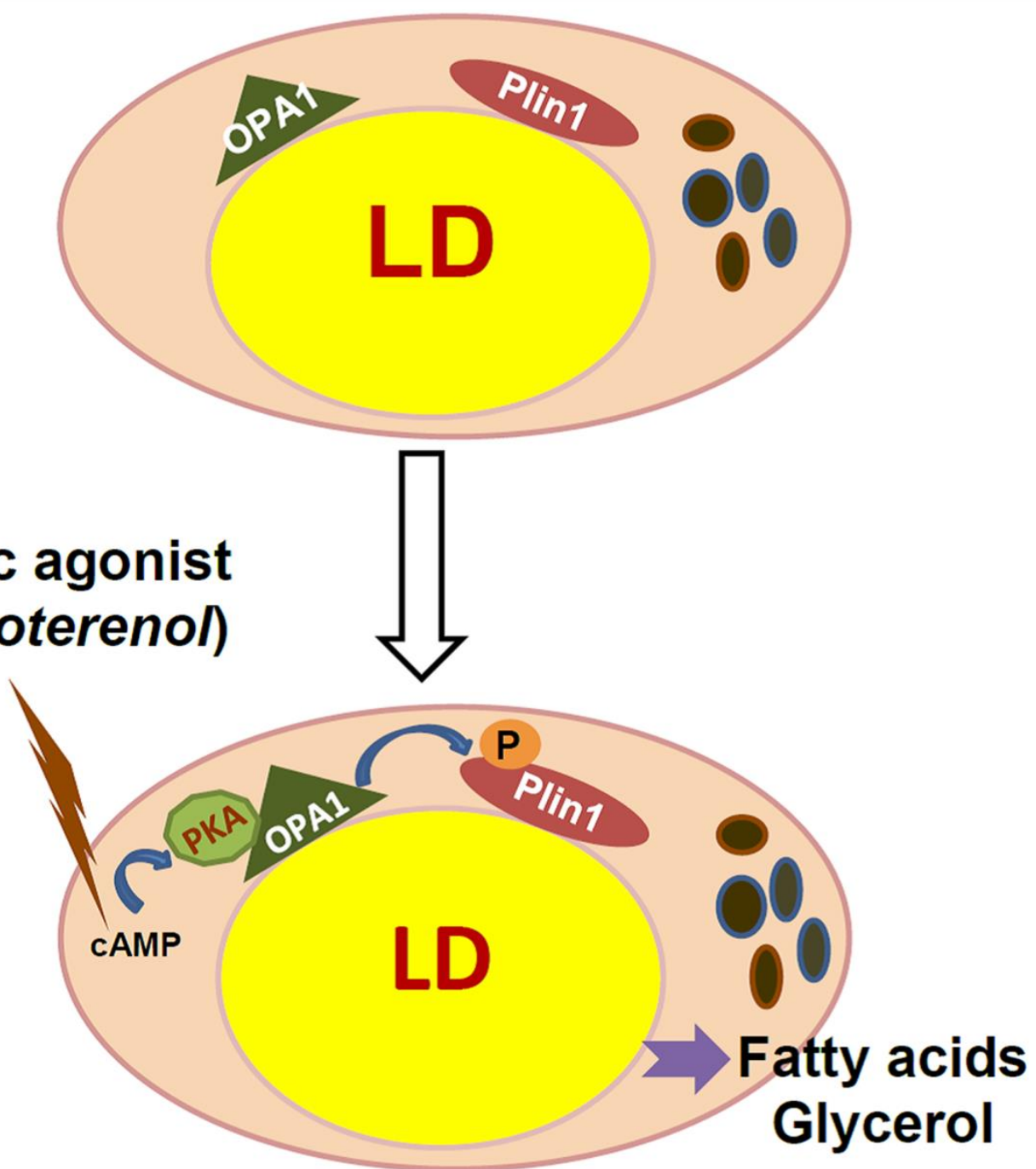
Figure 4.

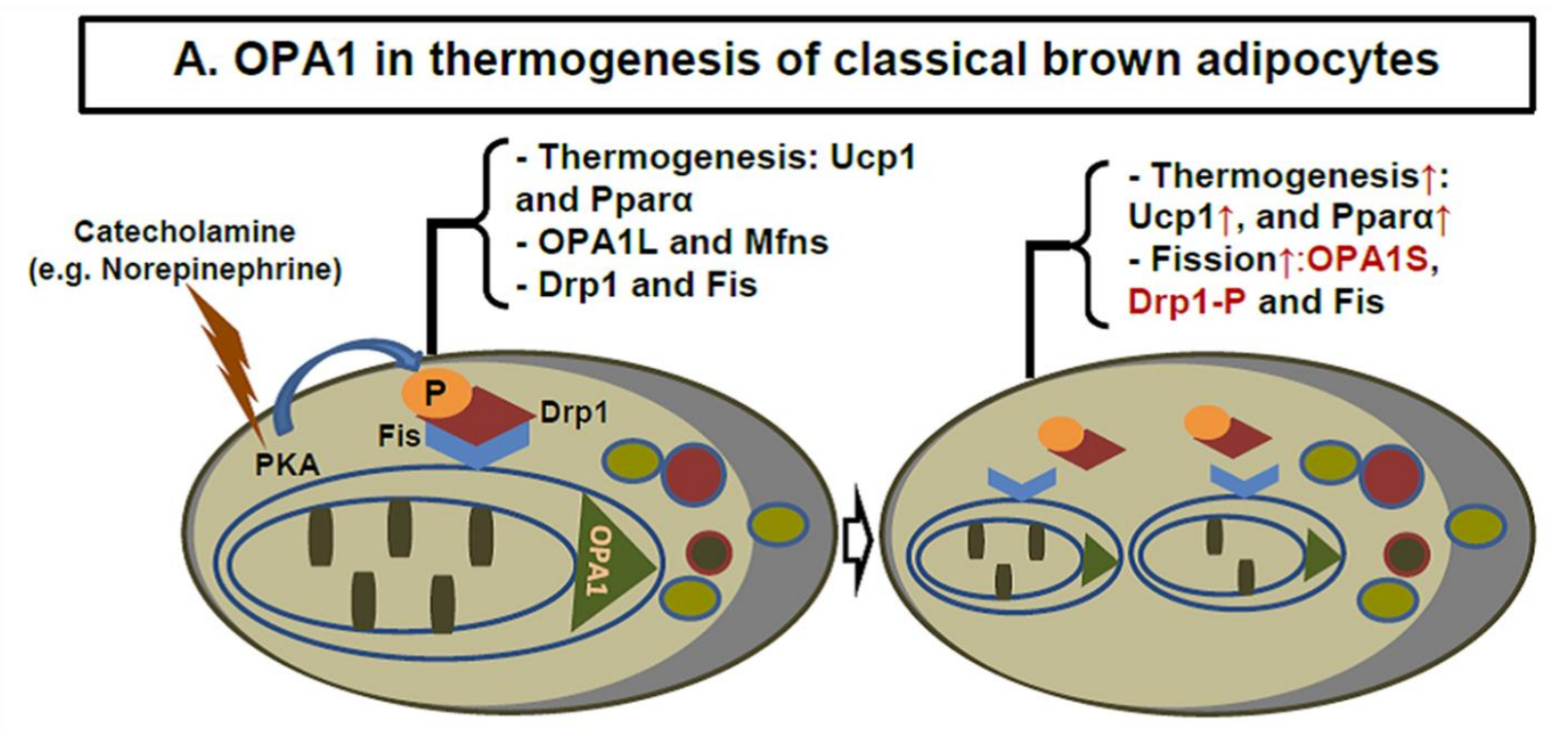

\section{B. OPA1 in thermogenesis of inducible brown adipocytes?}

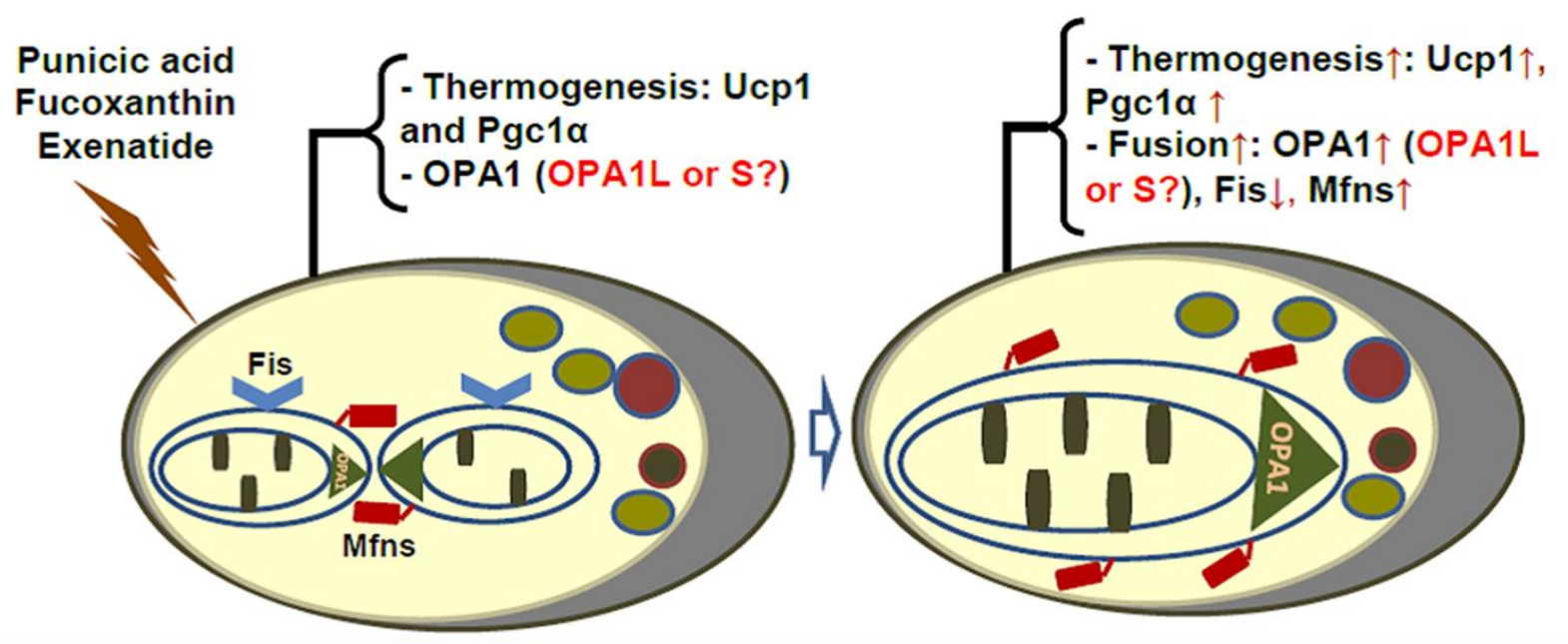

